\title{
RANCANG BANGUN ROBOT LINE FOLLOWER PEMADAM API MEMANFAATKAN FLAME SENSOR DAN BLUETOOTH BERBASIS ARDUINO
}

\author{
Badrut Tamam $^{1}$, Jusuf Bintoro ${ }^{2}$, Pitoyo Yuliatmojo ${ }^{3}$ \\ ${ }^{1}$ Mahasiswa Prodi Pendidikan Teknik Elektronika Fakultas Teknik Universitas Negeri Jakarta \\ ${ }^{2,3}$ Dosen Prodi Pendidikan Teknik Elektronika Fakultas Teknik Universitas Negeri Jakarta \\ E-mail: 1badruttamam046@gmail.com²j_bintoro_2012@yahoo.com ${ }^{3} @$ pitoyo_ok@yahoo.co.id
}

\begin{abstract}
Abstrak - Tujuan penelitian ini adalah membuat sistem monitoring ruangan yang berfungsi untuk memantau keberadaan api di dalam ruangan, dan membuat robot yang bisa memadamkan api secara otomatis berdasarkan hasil monitoring ruangan dengan memanfaatkan flame sensor yang digunakan untuk mendeteksi api di dalam ruangan dan memanfaatkan komunikasi bluetooth untuk mengirim informasi dari ruangan ke robot.Penelitian ini dilakukan dengan menggunakan metode penelitian dan pengembangan (Research and Development) yang meliputi perencanaan, analisis kebutuhan perancangan, pengujian, implementasi perangkat keras (Hardware) dan implementasi perangkat lunak (Software). Hasil dari penelitian menunjukan bahwa robot line follower pemadam api memanfaatkan flame sensor dan bluetooth berbasis Arduino yang telah dirancang sebelumnya berhasil dibuat, dan robot line follower pemadam api memanfaatkan flame sensor dan bluetooth berbasis Arduino ini sudah di coba di track yang mempunyai permukaan yang rata dengan ukuran $3 \mathrm{~m} \times 3 \mathrm{~m}$ dengan 3 prototype ruangan berukuran $90 \mathrm{~cm} \times 60 \mathrm{~cm}$ yang berada di dalam ruangan yang tidak tertembus cahaya matahari dan dengan api yang berasal dari nyala lilin. Pada saat tidak ada api di ruangan robot akan dalam kondisi diam di start dan saat ada api di ruangan, maka robot dapat langsung memadamkan api di ruangan yang terdeteksi terdapat titik apinya secara otomatis.
\end{abstract}

Kata-Kata Kunci: Robot Line Follower, Robot Pemadam Api, Flame Sensor, Bluetooth, Arduino.

\begin{abstract}
The purpose of this Researh is to Create a monitoring Room system that serves to monitor the presence of fire in the room, and make a robot that can extinguish the fire automatically based on the results of monitoring the room by using a flame sensor used to detect fire in the room and utilize bluetooth communication to send information From room to robot. This research is conducted by using research and development method which includes planning, design requirement analysis, testing, hardware implementation and software implementation. The results of the research show that the robot line follower fire extinguisher utilizes flame sensors and bluetooth-based Arduino that has been designed previously successfully made, and the robot line follower fire extinguisher utilizing flame sensor and bluetooth-based Arduino is already on the track that has a flat surface with the size $3 m \times 3 m$ with 3 prototype room measuring $90 \mathrm{~cm} \times 60 \mathrm{~cm}$ which is indoors indestructible sunlight and with fire coming from a candle flame. When there is no fire in room robot will be in silent condition at start and when there is fire in room, hence robot can directly Extinguish the fire in the detected room there is a fire point automatically.
\end{abstract}

Keywords: Line Follower robot, Fire Extinguisher Robot, Flame Sensor, Bluetooth, Arduino.

\section{PENDAHULUAN}

Ilmu pengetahuan dalam bidang IPTEK kini telah mengalami perkembangan yang sangat pesat, hal ini disebabkan karena semakin majunya sumber daya manusia yang ada dan semakin butuhnya manusia akan sistem atau alat yang efektif dan efisien untuk memenuhi kebutuhan kehidupannya dalam sehari-hari.

Salah satu perkembangan ilmu di bidang teknologi yang sedang berkembang dan masih sangat diminati oleh para peneliti saat ini adalah robot. Hampir semua bidang keteknikan dan industri di dunia ini menggunakan robot. Alasannya, robot mampu melakukan suatu pekerjaan tertentu secara terus-menerus dengan tahap-tahap yang telah ditentukan. Berbeda dengan manusia yang memiliki kecenderungan untuk mengalami kejenuhan jika dihadapkan pada pekerjaan yang sama sehingga kemungkinan untuk melakukan kesalahan kerja menjadi besar. 
Untuk dapat mengendalikan robot, para perancang robot membutuhkan suatu kontroler yang bertugas untuk mengatur semua kinerja robot agar sesuai dengan keinginan. Salah satu kontroler yang kini sedang populer adalah Arduino. Sudah banyak pemanfaatan robot untuk menggantikan pekerjaan manusia, Salah satu fungsi robot ialah sebagai pencegah terjadinya bencana kebakaran.

Kebakaran adalah sebuah musibah yang sering terjadi di daerah padat penduduk seperti Jakarta. Kebakaran ini disebabkan oleh banyak faktor, bisa dikarenakan kelalaian manusia yang lupa mematikan api di tempat-tempat tertentu seperti dapur, bisa dikarenakan oleh terjadinya arus pendek listrik baik pada instalasi maupun perangkat elektronik.

Robot dapat digunakan untuk menggantikan perkerjaan manusia, salah satu pekerjaan yang bisa dilakukan adalah sebagai pemadam api, pekerjaan seperti itu membutuhkan reaksi yang cepat karena kebakaran dapat dicegah ketika api belum menyebar luas.

Pergerakan robot tergantung pada lingkungan di mana robot tersebut akan ditempatkan. Jika robot ditempatkan di tempat yang tidak rata maka robot akan menggunakan kaki sebagai alat geraknnya. Sedangkan Di lingkungan yang memiliki alas yang rata robot bisa menggunakan roda sebagai media geraknnya.

Dalam penerapannya, robot membutuhkan media untuk berpindah dari satu tempat ke tempat yang lain. Salah satu media yang saat ini sedang populer adalah media garis berwarna hitam, salah satu alasannya adalah karena garis hitam mudah dibuat, bisa dengan menggunakan isolasi listrik atau yang lainnya. Robot yang bertugas untuk mengikuti garis dinamakan robot line follower.

\section{METODOLOGI PENELITIAN}

Penelitian dilaksanakan di Laboratorium Mekatronika dan Robotika Teknik Elektro FT-Universitas Negeri Jakarta, pada bulan Desember 2016 - Juli 2017.

Metode yang digunakan dalam merancang Robot Line Follower Pemadam Api Memanfaatkan Flame Sensor dan Bluetooth Berbasis Arduino menggunakan metode research and development (penelitian dan pembangunan).Tahap-tahap metodologi penelitian dapat dilihat pada Gambar 1

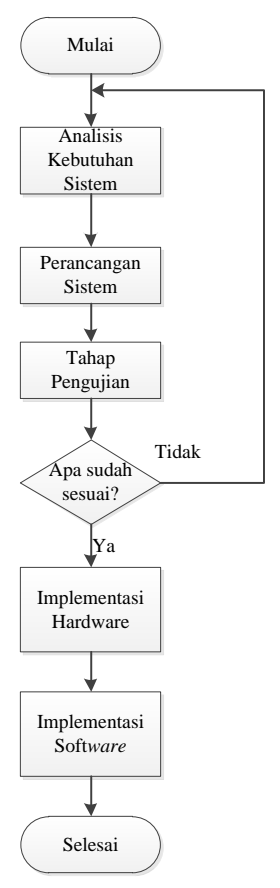

\section{Gambar 1 Tahap-tahap Metodologi Penelitian Perancangan alat}

\section{HASIL DAN PEMBAHASAN}

\section{A. Deskripsi Data}

Pada bab ini membahas mengenai hasil pembuatan bagian-bagian alat yang telah dirancang pada bagian perancangan perangkat keras di BAB III dan membahas mengenai pengujian robot line follower pemadam api memanfaatkan flame sensor dan bluetooth berbasis Arduino, dimana pada alat ini arduino mega 2560 dan arduino Uno telah diunggah program yang sesuai dengan flowchart robot dan monitoring ruangan pada BAB III. Gambar 4.1 adalah gambar robot line follower yang sudah berhasil dibuat.

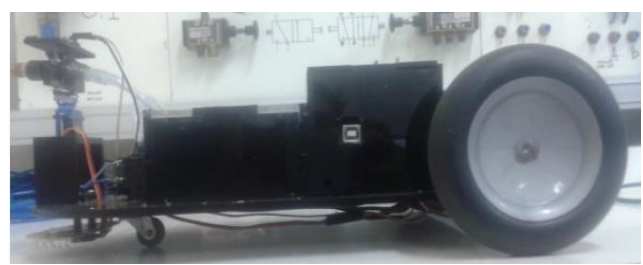

Gambar 4.1 Robot Line Follower

\section{B. Pengujian Flame Sensor KY-026}

Pengujian flame sensor KY-026 bertujuan untuk mengetahui data nilai analog yang dibaca oleh flame sensor saat ada api dan saat tidak ada api, serta untuk mengetahui data nilai analog yang dibaca oleh flame sensor pada jarak-jarak tertentu. Data hasil 
pengujian flame sensor KY-026 dapat dilihat pada Tabel 1. dan Tabel 2. berikut.

Tabel 1. Data Hasil Pengujian Flame Sensor

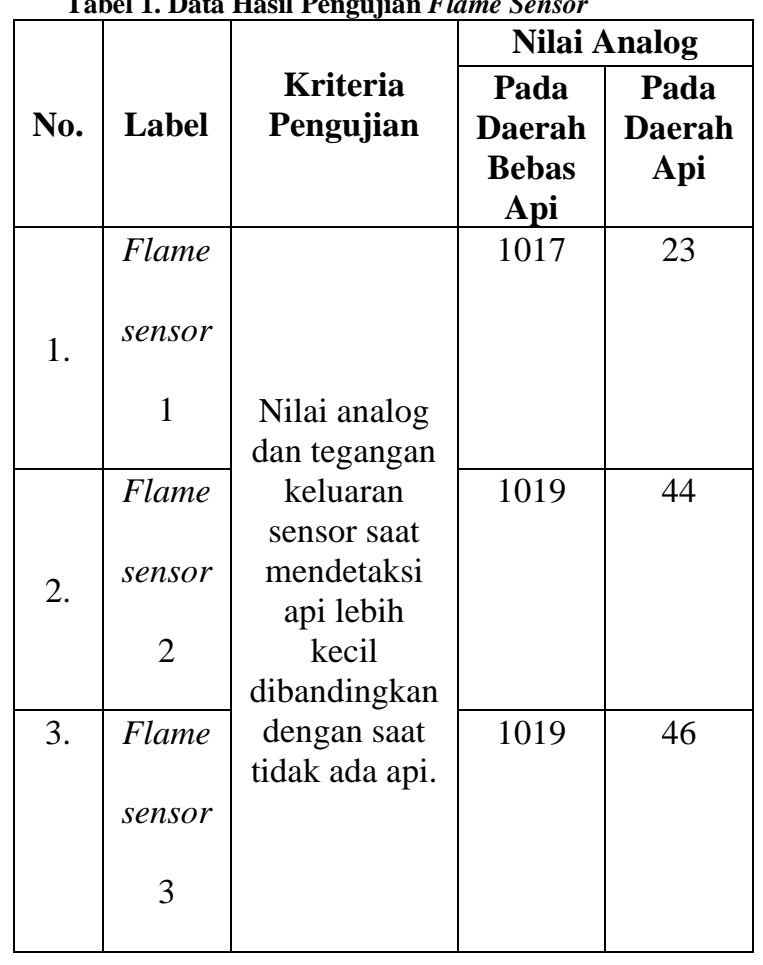

Tabel 2. Data Hasil Pengujian Flame Sensor pada

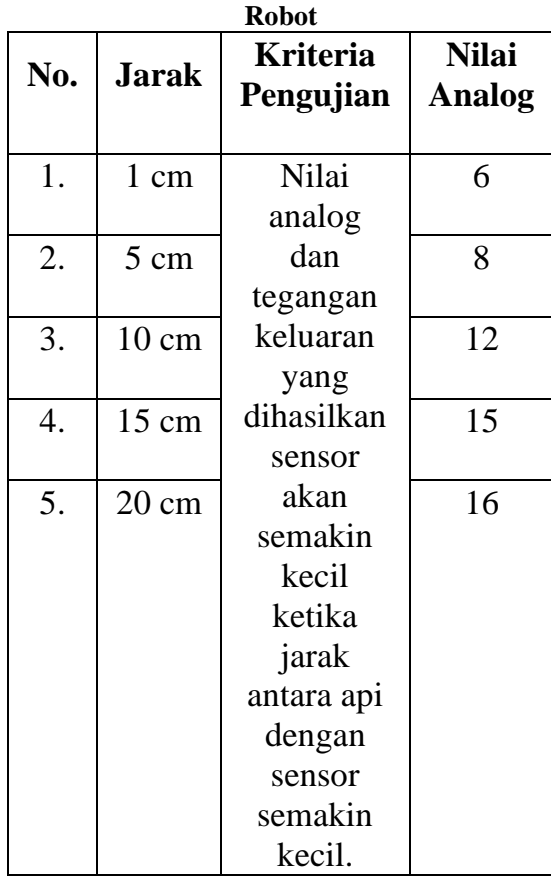

\section{Hasil Pengujian Komunikasi Bluetooth HC-05}

Pengujian komunikasi serial bluetooth bertujuan untuk menguji komunikasi antara dua perangkat modul bluetooth HC-05.
Selain itu pengujian ini bertujuan untuk mengetahui apakah modul HC-05 bisa dikendalikan menggunakan Arduino atau tidak. Data hasil pengujian Komunikasi Bluetooth HC-05 dapat dilihat pada Tabel 3 berikut.

\begin{tabular}{|c|c|c|c|c|}
\hline \multicolumn{5}{|c|}{$\begin{array}{l}\text { Tabel 3. Data Hasil Pengujian Komunikasi } \\
\text { Bluetooth HC-05 }\end{array}$} \\
\hline o. & $\begin{array}{c}\text { Penguji } \\
\text { an arah } \\
\text { komuni } \\
\text { kasi }\end{array}$ & $\begin{array}{c}\text { Data } \\
\text { yang } \\
\text { Akan } \\
\text { dikri } \\
\text { rm }\end{array}$ & $\begin{array}{c}\text { Kriter } \\
\text { ia } \\
\text { penguj } \\
\text { ian }\end{array}$ & $\begin{array}{c}\text { Data } \\
\text { yang } \\
\text { terece } \\
\text { tak di } \\
\text { serial } \\
\text { monit } \\
\text { or } \\
\text { Ardui } \\
\text { no } \\
\text { IDE }\end{array}$ \\
\hline 1. & Pengiri & 0 & $\begin{array}{l}\text { Data } \\
\text { vano }\end{array}$ & 0 \\
\hline 2. & $\begin{array}{c}\text { man dan } \\
\text { peneria }\end{array}$ & 1 & & 1 \\
\hline 3. & & 2 & & 2 \\
\hline 4. & $\begin{array}{c}\text { Transim } \\
\text { iter } \\
\text { bluetoot } \\
\text { h master } \\
\text { kepada } \\
\text { bluetoot } \\
\text { h slave }\end{array}$ & 3 & $\begin{array}{c}\text { sama } \\
\text { dengan } \\
\text { data } \\
\text { yang } \\
\text { dikirim } \\
\text { oleh } \\
\text { master }\end{array}$ & 3 \\
\hline
\end{tabular}

\section{Pengujian Sensor Garis}

Pengujian ini bertujuan untuk mengetahui apakah sensor garis dapat memberikan perubahan nilai ADC (Analog to Digital Converter) sesuai dengan perubahan cahaya yang diterima dari pantulan cahaya yang berasal dari jalur. Data hasil pengujian sensor garis dapat dilihat pada Tabel 4.berikut.

Tabel 4. Data Hasil Pengujian Sensor Garis

\begin{tabular}{|l|c|c|c|c|}
\hline \multirow{2}{*}{ No. } & \multirow{2}{*}{ Label } & $\begin{array}{c}\text { Kriteria } \\
\text { Pengujian }\end{array}$ & \multicolumn{2}{|c|}{ Nilai Analog } \\
\cline { 3 - 4 } & & $\begin{array}{c}\text { Alas } \\
\text { Putih }\end{array}$ & $\begin{array}{c}\text { Alas } \\
\text { Hitam }\end{array}$ \\
\hline
\end{tabular}




\begin{tabular}{|c|c|c|c|c|}
\hline 1. & $\begin{array}{c}\text { Sensor } \\
1\end{array}$ & \multirow{10}{*}{$\begin{array}{c}\text { Nilai analog } \\
\text { dan tegangan } \\
\text { keluaran } \\
\text { yang } \\
\text { dihasilkan } \\
\text { sensor saat } \\
\text { berada di } \\
\text { atas garis } \\
\text { hitam akan } \\
\text { lebih besar } \\
\text { dibandingkan } \\
\text { pada saat } \\
\text { berada di } \\
\text { garis putih }\end{array}$} & 39 & 744 \\
\hline 2. & $\begin{array}{c}\text { Sensor } \\
2\end{array}$ & & 37 & 630 \\
\hline 3. & $\begin{array}{c}\text { Sensor } \\
3\end{array}$ & & 41 & 775 \\
\hline 4. & $\begin{array}{c}\text { Sensor } \\
4\end{array}$ & & 38 & 700 \\
\hline 5. & $\begin{array}{c}\text { Sensor } \\
5\end{array}$ & & 38 & 689 \\
\hline 6. & $\begin{array}{c}\text { Sensor } \\
6\end{array}$ & & 38 & 646 \\
\hline 7. & $\begin{array}{c}\text { Sensor } \\
7\end{array}$ & & 37 & 655 \\
\hline 8. & $\begin{array}{c}\text { Sensor } \\
8\end{array}$ & & 36 & 418 \\
\hline 9. & $\begin{array}{c}\text { Sensor } \\
9\end{array}$ & & 41 & 666 \\
\hline 10. & $\begin{array}{c}\text { Sensor } \\
10\end{array}$ & & 40 & 578 \\
\hline
\end{tabular}

\section{E. Hasil Pengujian Modul LCD 16x2 dan} I2C LCD

Pengujian modul I2C LCD dan Modul LCD 16x2 bertujuan untuk mengetahui apakah kedua modul tersebut bisa digunakan untuk menampilkan karakter yang diinginkan melalui kontroler Arduino Mega 2560. Data hasil pengujian modul LCD 16x2 dan I2C LCD dapat dilihat ke dalam Tabel 5.

Tabel 5. Data Hasil Pengujian Modul LCD 16x2 dan

\begin{tabular}{|c|c|c|c|}
\hline & & & \\
\hline $\mathrm{N}$ & Karakte & Kriteria & Karakter \\
\hline o. & r Yang & $\begin{array}{c}\text { Pengujia } \\
\text { n }\end{array}$ & Yang \\
\hline
\end{tabular}

\begin{tabular}{|c|c|c|c|}
\hline & $\begin{array}{c}\text { Ingin } \\
\text { ditampil } \\
\text { kan } \\
\text { Arduino } \\
\text { Mega }\end{array}$ & & $\begin{array}{l}\text { Tampil } \\
\text { Pada } \\
\text { LCD }\end{array}$ \\
\hline 1. & $\begin{array}{l}\text { Menceta } \\
\text { k } \\
\text { Karakter } \\
\text { Huruf }\end{array}$ & $\begin{array}{c}\text { LCD } \\
\text { Menampil } \\
\text { kan } \\
\text { karakter } \\
\text { Huruf }\end{array}$ & WDEFGHIJKLMNO \\
\hline 2. & $\begin{array}{l}\text { Menceta } \\
\text { k } \\
\text { Karakter } \\
\text { Angka }\end{array}$ & $\begin{array}{c}\text { LCD } \\
\text { Menampil } \\
\text { kan } \\
\text { karakter } \\
\text { Angka }\end{array}$ & 123456789 \\
\hline 3. & $\begin{array}{c}\text { Menceta } \\
\text { k } \\
\text { Karakter }\end{array}$ & $\begin{array}{c}\text { LCD } \\
\text { Menampil } \\
\text { kan } \\
\text { karakter } \\
\text { " } \rightarrow \text { " }\end{array}$ & \\
\hline
\end{tabular}

F. Hasil Pengujian Driver Motor dengan Menggunakan L298N

Pengujian driver motor dengan menggunakan L298N adalah untuk mengetahui apakah driver motor dengan menggunakan L298N yang mengendalikan arah putaran motor DC yang bertugas untuk menggerakan robot dapat dikendalikan oleh Arduino Mega 2560 atau tidak. Data hasil pengujian Driver Motor dengan Menggunakan L298N dapat dilihat di Tabel 6 dan Tabel 7.

Tabel 6. Data Hasil Pengujian Driver Motor dengan Menggunakan L298N 


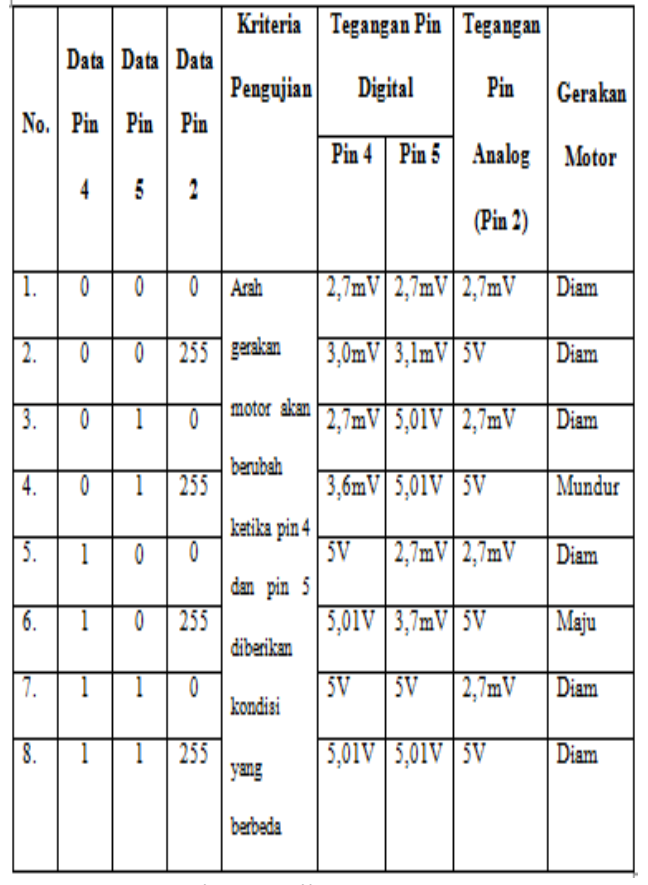

Tabel 7 Hasil Pengujian Tegangan Keluaran Rangkaian Driver L298N

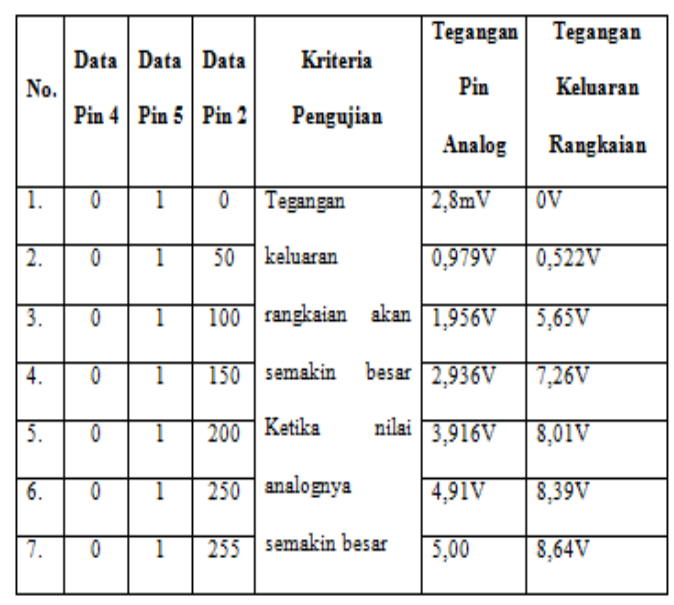

\section{G. Pembahasan Hasil Penelitian}

Pengujian alat secara keseluruhan dilakukan dengan menggabungkan semua subsistem yang ada, penggabungan subsistem tersebut diantaranya adalah terdiri dari modul flame sensor KY-026, modul bluetooth HC05, sensor garis, shield Arduino Mega 2560, shield Arduino Uno, Arduino Mega 2560, Arduino Uno, motor DC sebagai penggerak dan driver motor L298N sebagai pengendali motor.

Berdasarkan hasil seluruh pengujian subsistem yang sudah dilakukan, diketahui bahwa rancang bangun robot line follower pemadam api memanfaatkan flame sensor dan bluetooth berbasis Arduino ini berfungsi sesuai dengan perancangannya dengan presentase keberhasilan robot bisa memadamkan api sebesar 95,24\% dan pengujian subsistem yang sudah dilakukan sudah sesuai dengan kriteria pengujian yang diinginkan.

\section{KESIMPULAN}

Berdasarkan hasil penelitian yang sudah dilakukan, melalui tahap perancangan, pembuatan dan pengujian robot line follower pemadam api memanfaatkan flame sensor dan bluetooth berbasis Arduino dapat disimpulkan bahwa: 1) Perancangan robot line follower pemadam api memanfaatkan flame sensor dan bluetooth berbasis Arduino dapat direalisasikan sesuai dengan perancangan yang sudah dilakukan.. 2)Untuk merancang robot line follower pemadam api dibutuhkan base robot, air, sensor garis, flame sensor, Arduino, motor DC dan driver motor DC. 3) Untuk membangun sistem monitoring ruangan dibutuhkan flame sensor, Arduino dan bluetooth. 4) Untuk menguji robot line follower pemadam api memanfaatkan flame sensor dan bluetooth berbasis Arduino dibutuhkan track berukuran $3 \mathrm{~m} \times 3 \mathrm{~m}$. Track tersebut berupa garis berwarna hitam di atas alas berwarna putih dan 3 prototype ruangan yang berukuran $90 \mathrm{~cm} \times 60 \mathrm{~cm}$ yang berada di dalam ruangan yang tidak tertembus cahaya matahari dan dengan api yang berasal dari nyala lilin.

\section{REFRENSI}

[1] Andrianto, H. \& Darmawan, A., (2016). Arduino Belajar Cepat dan Pemrograman. Bandung: Informatika Bandung.

[2] Banzi, M. (2005). ArduinoBoardUno. Dipetik November 27, 2016, dari Arduino web site: www.arduino.cc

[3] [FT] Fakultas Teknik. 2015. Buku Panduan Penyusunan Skripsi Dan Non Skripsi. Jakarta: Fakultas Teknik, Universitas Negeri Jakarta.

[4] Kadir, A. (2013). Panduan Praktis Mempelajari Aplikasi Mikrokontroler dan Pemrogramannya menggunakan Arduino. Yogyakarta: C.V ANDI OFFSET. 
[5] Nalwan, A. (2012). Teknik Rancang Bangun Robot. Yogyakarta: CV. ANDI OFFSET.

[6] Pratama, O. W., dkk., (2014). Sistem Kendali Gerak Robot Menggunakan PC Berbasis Bluetooth. :3.

[7] Rachmad, A. (2016). Rancang Bangun Robot Pemanjat Tiang dan Pemasang Propeller Menggunakan Gripper Elektro Pneumatik sebagai Hybrid Robot pada Kontes Robot Abu Indonesia 2016.[Skripsi]. Jakarta: Fakultas Tenik, Univeritas Negeri Jakarta.
[8] Ramli, S. (2010). Sistem Manajemen Keselamatan dan Kesehatan Kerja. Jakarta: DIAN RAKYAT.

[9] Sanjaya, M. (2016). Panduan Praktis Membuat Robot Cerdas Menggunakan Arduino dan Matlab. Yogyakarta: CV. ANDI OFFSET.

[10] Setiawan, A. (2015). Robot Pemadam Api dengan Tracking Target Menggunakan Accelerometer Berbasis Mikrokontroler Arduino Due. :2. 